Thomas L. Gertzen

\title{
Orientalismus und Antisemitismus
}

\author{
Vergleichende Betrachtungen zu Ernest Renan, Paul de \\ Lagarde, Eduard Meyer und Friedrich Delitzsch
}

\section{Juden als Orientalen und „jüdische“ Orientalistik}

Das hier umrissene Forschungsfeld ist weitläufig und komplex. Zum einen umfasst es die Auseinandersetzung mit den wechselseitigen Abhängigkeiten der Forschungen sowohl der Jüdischen Studien als auch (verschiedener) orientalistischer Disziplinen, ${ }^{1}$ zum anderen erfordert es die Beschäftigung mit individuellen Gelehrtenbiografien. ${ }^{2}$ Dabei müssen sich die Ergebnisse in den übergeordneten Rahmen der Wissenschaftsgeschichte und Wissenschaftssoziologie ebenso einordnen lassen, wie in den (noch weiter gefassten) der allgemeinen Kultur- und Geistesgeschichte. ${ }^{3}$

Auch Antisemitismus und Orientalismus befinden sich in einem besonderen Spannungsverhältnis zueinander. Juden werden als Vertreter ,orientalischer* Kultur ausgegrenzt. ${ }^{4}$ Das Konzept des Orientalismus wird gewissermaßen als

1 Einen Überblick bieten: Rohde, Achim: Unter Südländern. Zur Geschichte der Orientalistik und Judaistik in Deutschland. In: Zeitschrift für Geschichtswissenschaft (ZfG) 58, 7/8 (2010). S. 639652; Thulin, Mirjam: Zeitschrift der Deutschen Morgenländischen Gesellschaft. In: Enzyklopädie jüdischer Geschichte und Kultur 6 (2015). S. 516-520.

2 Als Beispiele: Haber, Peter: Zwischen jüdischer Tradition und Wissenschaft. Der ungarische Orientalist Ignác Goldziher (1850 - 1921). Köln 2006 (Lebenswelten Osteuropäischer Juden 10); Thulin, Mirjam: Kaufmanns Nachrichtendienst. Ein jüdisches Gelehrtennetzwerk im 19. Jahrhundert. Göttingen 2012; Voss, Susanne u. Dietrich Raue (Hrsg.): Georg Steindorff und die deutsche Ägyptologie im 20. Jahrhundert. Wissenshintergründe und Forschungstransfer. Berlin 2016 (Zeitschrift für Ägyptische Sprache und Altertumskunde, Beihefte 5); Gertzen, Thomas L.: Judentum und Konfession in der Geschichte der deutschsprachigen Ägyptologie. Berlin 2017 (Europäisch-jüdische Studien, Beiträge 32).

3 Hierzu: Marchand, Suzanne: German Orientalism in the Age of Empire. Religion, Race and Scholarship. Cambridge 2009.

4 Heschel, Susannah: Revolt of the Colonized: Abraham Geiger's Wissenschaft des Judentums as a challenge to Christian Hegemony in the Academy. In: New German Critique 77 (1999), S. 61- 85; Kalmar, Ivan D. u. Derek J. Penslar (Hrsg.): Orientalism and the Jews. Cambridge (Mass.) 2005; Rohde, Achim: Der Innere Orient. Orientalismus, Antisemitismus und Geschlecht im Deutschland des 18. bis 20. Jahrhunderts. In: Die Welt des Islams 45, 3 (2005). S. 370 -411; Kirchhoff, Markus: 
,Gegenmittel' $\mathrm{zu}$ einer vermeintlichen ,Antisemitismuskeule` im Kontext des israelisch-palästinensischen Nahost-Konfliktes instrumentalisiert. ${ }^{5}$ Womit deutlich wird, dass historische Forschung in diesem Bereich auch einen unmittelbaren Aktualitätsbezug erlangen kann.

In diesem Beitrag sollen jedoch nicht diese übergeordneten Forschungsdiskurse oder jüdische Orientalisten und ihre Ausgrenzung im deutschen akademischen Betrieb, ${ }^{6}$ sondern vielmehr solche Gelehrte im Mittelpunkt stehen, die innerhalb orientalistischer Forschungen einen Beitrag zur Entwicklung des ,akademischen Antisemitismus' geleistet haben.

\section{Jenseits der Disziplinengrenzen: Alttestamentliche Studien und Forschungen zum (Alten) Orient}

Die bisher gemachten Ausführungen haben einen Untersuchungsbereich noch bewusst ausgeklammert, nämlich das Verhältnis (alt-)orientalistischer Forschung zu den alttestamentlichen Studien, bzw. zur Theologie. Die hier vorzustellenden Protagonisten lassen sich mit Ausnahme Eduard Meyers, welcher Althistoriker war, gleichwohl aber auch schwerpunktmäßig die Geschichte des alten Orients erforscht hat, allesamt als Orientalisten bezeichnen. Der Fall von Paul de Lagarde bildet dabei eine weitere, vielleicht sogar noch entscheidendere Ausnahme, weil er, obwohl Inhaber eines Lehrstuhls für Orientalistik, ausdrücklich „Theologe nicht Orientalist“ sein wollte. ${ }^{7}$ Das besondere Spannungsverhältnis von Orienta-

Erweiterter Orientalismus. Zu euro-christlichen Identifikationen und jüdischer Gegengeschichte im 19. Jahrhundert. In: Jüdische Geschichte als Allgemeine Geschichte. Festschrift für Dan Diner zum 60. Geburtstag. Hrsg. v. Raphael Gross u. Yif'at Weiss. Göttingen 2006. S. 99-119; Kirchhoff, Markus: Zwischen Orientromantik und Rassismus. Juden als Araber und Europas Andere. In: Kulturkonflikte - Kulturbegegnungen. Juden, Christen und Muslime in Geschichte und Gegenwart. Hrsg. v. Gisbert Gemein. Bonn 2011. S. $430-442$.

5 Vgl. Mendel, Meron u. David Uhlig: Challenging Postcolonial: Antisemitismuskritische Perspektiven auf postkoloniale Theorie. In: Fragiler Konsens: Antisemitismuskritische Bildung in der Migrationsgesellschaft. Hrsg. v. Meron Mendel u. Astrid Messerschmidt. Frankfurt a.M. 2017. S. $249-268$.

6 Vgl. hierzu: Hammerstein, Notker: Antisemitismus und deutsche Universitäten 1871-1933. Frankfurt a. M. 1995.

7 Mangold, Sabine: Eine „weltbürgerliche Wissenschaft“. Die deutsche Orientalistik im 19. Jahrhundert. Stuttgart 2004. S. 149. 
listik und Theologie im Übergang vom 19. zum 20. Jahrhundert ist von Suzanne Marchand treffend beschrieben worden:

One striking aspect of philistine ignorance against which many members of this generation rebelled was the still conventional belief that the aim of understanding 'the Orient' was to explicate the Old Testament. ${ }^{8}$

Daher leitet sie auch ihr Konzept des „Furor Orientalis“ ab, der als eine Art Emanzipationsbemühung der Orientalistik aus der Rolle einer Hilfswissenschaft der Theologie zu verstehen ist. Allerdings bot sich den Orientalisten auch die Möglichkeit, den Vertretern der christlichen Theologien aus einer gewissen Verlegenheit $\mathrm{zu}$ helfen:

Here [at the theological faculties] Christian scholarship had for centuries emphasized Christianity's superseding of Judaism. But until the end of the fin de siècle, it was hard for most Christians to get around the Jews' contribution to Christian history and doctrine. It was the furor orientalis that helped to supply essential tools for this severing operation; [...] it succeeded in pushing the history of the ancient [...] Assyrians [...] to the fore, mostly at the cost of the ancient Hebrews. ${ }^{9}$

Die historisch-kritische Methode hatte Grundlagen christlichen Glaubens in jüdischen Schriften erschlossen, bzw. verdeutlicht. Die durch Marchand skizzierte Strategie, der dadurch verunsicherten Theologie eine alternative Grundlage in den Texten und der sowohl sprachlichen als auch ethnologischen (im damaligen Sprachgebrauch auch ,rassekundlichen') Erforschung des alten Orients zu erschließen und somit den jüdischen Einfluss zu marginalisieren, ${ }^{10}$ soll im Folgenden näher untersucht werden. Dabei werden Auseinandersetzungen mit den Vertretern der jüdischen Bibelwissenschaft, bzw. der Wissenschaft des Judentums $^{11}$ nur am Rande behandelt. Es geht hier vorrangig um die Instrumentalisierung orientalistischer Forschung (im weitesten Sinne) für den oben genannten Zweck.

8 Marchand, German Orientalism in the Age of Empire (wie Anm. 3), S. 220.

9 Marchand, German Orientalism in the Age of Empire (wie Anm. 3), S. 221.

10 Einen interessanten Vergleich bieten die Versuche jüdischer Orientalisten, sich durch islamwissenschaftliche Forschung als Teil des Okzidents zu profilieren, vgl. Heschel, Susannah: German Jewish Scholarship on Islam as a Tool for De-Orientalizing Judaism. In: New German Critique 117, Bd. 39.3 (2012). S. 91-107.

11 Wiese, Christian: Wissenschaft des Judentums und protestantische Theologie im wilhelminischen Deutschland. Ein Schrei ins Leere?. Tübingen 1999. 


\section{Juden und Semiten - Ernest Renan (1823-1892)}

Der biografische Hintergrund von Ernest Renan weist einige bemerkenswerte Aspekte auf. ${ }^{12}$ Er begann seine Laufbahn 1838 als Seminarist in Saint-Nicolas-duChardonnet in Paris. Von dort wechselte er 1841 zum Seminar von Issy und ging 1843 an das Grand Séminaire de Saint-Sulpice, wo er 1844 die niederen Weihen empfing. 1845 jedoch verließ er das Seminar, aufgrund schwerwiegender Zweifel an der Historizität der Heiligen Schrift und der daraus abgeleiteten Dogmen ${ }^{13}$ und wandte sich der Tübinger Schule ${ }^{14} \mathrm{zu}$. Obwohl Franzose und Katholik, war er dem deutschen Geistesleben zugeneigt, was sich erst durch die Erfahrungen des deutsch-französischen Krieges von 1870/71 ändern sollte. ${ }^{15} 1859$ wurde er zum korrespondierenden Mitglied der Preußischen Akademie der Wissenschaften gewählt, ${ }^{16} 1860$ von der Bayerischen Akademie zum auswärtigen Mitglied. ${ }^{17} 1863$ veröffentlichte er als ersten Band seiner „Histoire des origines du christianisme“ das „Vie de Jésus“. Infolge seiner kritisch-historisierenden Forschung wurde seine 1862 erfolgte Berufung auf einen Lehrstuhl für orientalische Sprachen am Collège de France, auf Druck der katholischen Kirche, ausgesetzt. Erst 1870 wurde er rehabilitiert und erst 1879 zum Mitglied der Académie française gewählt.

Juden und Judentum spielen in Renans Euvre eine zentrale Rolle. ${ }^{18}$ Neben seinem Hauptwerk zur „Histoire du peuple d'Israël“19 ist es v.a. sein Vortrag zum „Judaïsme comme race et comme religion“ von 1883, der ihn manchen Beob-

12 Soweit nicht anders angegeben, beruhen die biografischen Daten auf: Binder, Hans-Otto: Renan, Ernest. In: Biographisch-Bibliographisches Kirchenlexikon (BBKL) 8. Herzberg 1994. Sp. $23-27$.

13 Vgl. hierzu: Gay, Peter: Die Macht des Herzens. Das 19. Jahrhundert und die Erforschung des Ich. München 1997. S. 160-162.

14 Vgl. Geiselmann, Joseph R.: Die katholische Tübinger Schule: Ihre theologische Eigenart. Freiburg i.B. 1964.

15 Er verarbeitete diese Erfahrungen u.a. in: Renan, Ernest: La Réforme intellectuelle et morale. Paris 1871; dazu Mian, Aristide: Renan on War and Peace. In: The American Scholar 15.1 (1945). S. $90-96$.

16 Berlin-Brandenburgische Akademie der Wissenschaften, Mitglieder der Vorgängerakademien. http://www.bbaw.de/die-akademie/akademiegeschichte/mitglieder-historisch/alphabeti sche-sortierung?altmitglied_id=2243\&letter=R (18.04.2018).

17 Bayerische Akademie der Wissenschaften, Verstorbene Mitglieder. https://www.badw.de/gelehrtengemeinschaft/verstorbene.html (18.04.2018).

18 Vgl. Hoffmann, Dieter M.: Renan und das Judentum. Die Bedeutung des Volkes Israel im Werk des „Historien philosophe“. Würzburg 1988.

19 Erschienen in 5 Bde. (1887-1893). 
achtern als Wegbereiter eines modernen Rassenantisemitismus erscheinen ließ. ${ }^{20}$ Die Hebräer, so Renan, wären durch ihre Umwelt religiös geprägt worden: „Le désert est monothéiste. “21 und hätten dadurch einen entscheidenden Beitrag zur Entwicklung menschlicher Zivilisation geleistet. ${ }^{22}$ Allerdings seien sie als Semiten den Ariern in praktisch allen anderen Bereichen grundsätzlich unterlegen:

Je suis donc le premier à reconnaître que la race sémitique, comparée à la race indo-européenne, représente réellement une combinaison inférieure de la nature humaine. ${ }^{23}$

Der Glaube an die Auserwählung des Volkes Israel erschien Renan als wichtigster Grund für die vermeintliche Erstarrtheit der jüdischen Religion und für die Anfeindungen durch die die Juden umgebenden Mehrheitsgesellschaften:

Pleins du leur sentiment de leur supériorité, [...] amenés par leur Loi à un isolement qui paraissait du dédain, les Juifs passaient pour mauvais voisins et l'étaient en effet. Ils étaient détestés des peuples qui les entouraient. Un tel fait se produit, à tous les siècles, d'une façon trop constante pour il n'ait pas sa raison d'être. ${ }^{24}$

Allerdings unterschied Renan zwischen den Angehörigen der jüdischen Religion und der semitischen Rasse. Unter den Ersteren wähnte er, unter Berufung auf Cassius Dio, frühzeitig auch Angehörige anderer Rassen: „Dion Cassius sait, qu'il y a des juifs de race, [...] mais qu'à côté d'eux, il y a des juifs, qui ne sont pas juifs de sang“. ${ }^{25}$ Auch ließe sich kein moderner ,jüdischer (Rasse-) Typ“ bestimmen: „Eh bien, le résultat de mon expérience est qu'il n'y a pas un type juif unique, mais qu'il y en a plusieurs“26. Im Gegensatz zu den Vertretern völkischer Konzepte in Deutschland ${ }^{27}$ betrachtete Renan die Vermischung der Rassen als etwas Positives und glaubte, dass langfristig Rassenzugehörigkeit an Bedeutung verlieren würde:

20 Dazu: Almog, Shmuel: The Racial Motif in Renan's Attitude to Jews and Judaism. In: Antisemitism through the ages. Hrsg. v. Shmuel Almog. Oxford 1988. S. 255-278.

21 Renan, Ernest: Euvres Complètes. Edition définitive établie par Henriette Psichari VIII. Paris 1958. S. 147; s.a. Renan, Ernest: Nouvelles considérations sur le caractère général des peuples sémitiques et en particulier sur leur tendance au monothéisme. In: Comptes-rendus des séances de 1 année - Académie des inscriptions et belles-lettres (crai) 3 (1859). S. 67-100.

22 Vgl. Renan, Ernest: De la part des peuples sémitiques dans l'histoire de la civilisation. Paris 1862.

23 Renan, Ernest: Histoire générale et système comparé des langues sémitiques. Paris 1855. S. 4

24 Renan, Ernest: Histoire du peuple d'Israël VI. Paris 1893. S. 369-370.

25 Renan, Ernest: Le judaïsme comme race et comme religion. Paris 1883. S. 16.

26 Renan, Le judaïsme (wie Anm. 25), S. 25.

27 Hierzu grundlegend: Puschner, Uwe: Die völkische Bewegung im wilhelminischen Kaiserreich. Sprache, Rasse, Religion. Bonn 2001. 
„Le fait de la race, capitale à l'origine, va toujours perdant de son importance“. ${ }^{28}$ Die Wahrnehmung der Juden als eine (ab-)gesonderte Gruppe wäre laut Renan demnach nicht auf „Rassenreinheit“ einer ,jüdischen Rasse“ zurückzuführen, sondern auf ihren religiösen Isolationismus. Diesen jedoch leitete Renan von der Unfähigkeit der Hebräer zur Weiterentwicklung ihrer religiösen Vorstellungen ab. Folgerichtig wird auch Jesus bei Renan zwar nicht als „rassisch“29 gleichwohl aber kulturell in Opposition zum Judentum charakterisiert, ,qui faisait de lui, dans le sein du judaïsme, un révolutionnaire au premier chef.“"30 Und dann sogar: „Ce

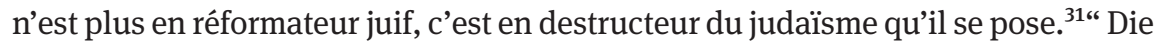
jüdischen Grundlagen des Christentums werden durch Renan nicht geleugnet, allerdings musste sich die neue Religion seiner Ansicht nach von dem Alten absetzen, ja sogar eine Gegenbewegung sein.

Das Judentum müsse als Religion überwunden werden, damit die vermeintliche Absonderung der Juden beendet und ein gesellschaftlicher Fortschritt erreicht werden könne. Auch wenn Renan dabei Rassismus und völkischen Konzepten eher eine Absage erteilt, bzw. auch diese überwinden will, vertritt er die Ansicht, dass die Juden aufhören müssten, Juden zu sein und ihre Weigerung, dies $\mathrm{zu}$ tun einerseits antisemitische Anfeindungen (schuldhaft) verursachen würde und andererseits dem Fortschritt der gesamten Menschheit im Wege stünde. Man kann den Antisemitismusbegriff unterschiedlich definieren bzw. historisch einordnen, ${ }^{32}$ eine judenkritische oder sogar judenfeindliche Haltung ist Renan nicht ohne weiteres abzusprechen.

28 Renan, Ernest: L’islamisme et la science. Paris 1883. S. 2.

29 Allerdings verweist Renan auf die starke „Vermischtheit“ der Galiläer; vgl. Renan, Ernest: Vie de Jésus. Paris 1863. S. 21-22 und später (S. 222) auf Jesu „Kampf gegen sein Blut“, woraus folge: „Jésus, en d'autres termes, n'est plus juif.“; vgl. hierzu: Fenske, Wolfgang: Wie Jesus zum „Arier“ wurde. Auswirkungen der Entjudaisierung Christi im 19. und zu Beginn des 20. Jahrhunderts. Darmstadt 2005. S. 72-73.

30 Renan, Vie de Jésus (wie Anm. 26), S. 86.

31 Renan, Vie de Jésus (wie Anm. 29), S. 221.

32 Hierzu: Botsch, Gideon: Von der Judenfeindschaft zum Antisemitismus. Ein historischer Überblick. In: Aus Politik und Zeitgeschichte (APuZ) 64, B 28-30 (2014). S. 10 -17. 


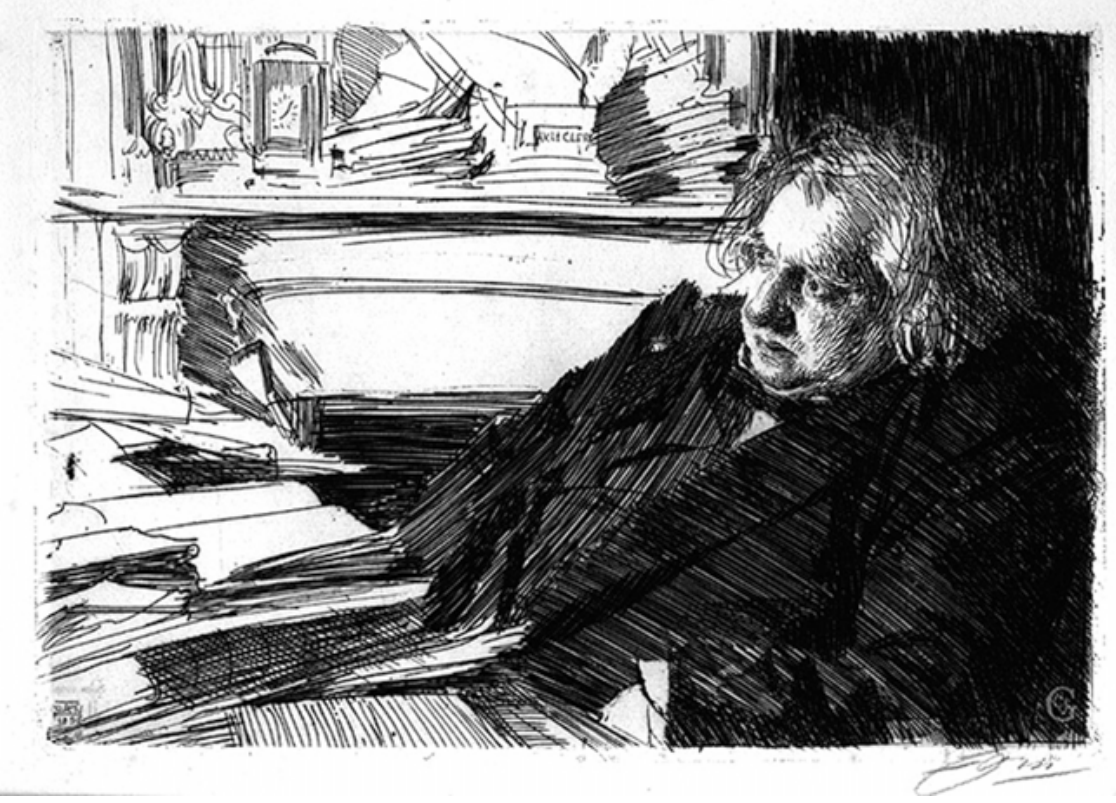

Abb. 5: Ernest Renan an seinem Schreibtisch auf einem Druck von Anders Leonard Zorn (C) Gemeinfrei: https://commons.wikimedia.org/wiki/File:ErnestRenan.jpg

\section{Vom Judentum zum Deutschtum - Paul de Lagarde (1827-1891)}

Auch die Biografie ${ }^{33}$ Paul Böttichers (ab 1854 de Lagarde) ist geprägt von zahlreichen Konflikten und - zumindest von ihm so wahrgenommenen - Benachteiligungen und Zurücksetzungen. Das belastete Verhältnis zu seinem Vater wird dabei als zumindest eine der Grundlagen seiner idiosynkratrischen und streitbaren Persönlichkeit angesehen. Nach dem 1844 begonnen Studium der Theologie und Orientalistik in Berlin, folgten zwar die üblichen akademischen Stationen der Promotion (1849) und Habilitation (1851), die erhoffte Berufung auf einen Lehrstuhl blieb allerdings zunächst aus. Dabei mangelte es Bötticher nicht an Selbstvertrauen, was es ihm auch erleichterte, erfolgreich königliche Stipendien einzuwerben, um seine Forschungsaufenthalte in ausländischen Bibliothe-

33 Ich stütze mich dabei im Wesentlichen auf: Sieg, Ulrich: Deutschlands Prophet. Paul de Lagarde und die Ursprünge des modernen Antisemitismus. München 2007. 
ken zu finanzieren. Einer davon führte ihn 1853 auch nach Paris, wo er Ernest Renan kennen lernte, welcher damals bei der Sammlung orientalischer Handschriften der Bibliothèque Nationale angestellt war. Die beiden Gelehrten verstanden sich gut und blieben auch eine Weile in brieflichem Kontakt. ${ }^{34}$ Ab 1853 war Bötticher an verschiedenen Gymnasien als Lehrer tätig. Die Frustration über diese seiner Forschung abträgliche und - seinem Empfinden nach - seiner Qualifikation unangemessene Tätigkeit, paarte sich allerdings mit großem Einsatz für die Ausbildung seiner Schüler. 1869 erfolgte schließlich die lange ersehnte Berufung auf einen Lehrstuhl in Göttingen, auf die 1876 noch die Wahl zum Mitglied der Königlichen Gesellschaft der Wissenschaften zu Göttingen folgen sollte. Der deutsch-französische Krieg regte Lagarde erstmals zu politischer Tätigkeit an, so dass er in einem anonymen Zeitungsartikel für die Annexion ElsassLothringens eintrat. Die seinerzeit durch Dritte erfolgte Veröffentlichung seiner früheren Bittgesuche an Napoleon III. sollten seiner vaterländischen Reputation allerdings zunächst einen gewissen Dämpfer versetzen.

Lagardes Haltung zum Judentum ist vielfach und ausführlich besprochen worden. ${ }^{35}$ An dieser Stelle sollen daher lediglich inhaltliche Bezüge zu den anderen behandelten Fallbeispielen diskutiert werden. Mit Renan verband Lagarde dabei sowohl eine kritische Haltung zum Alten Testament und dem Judentum, als auch eine gewisse Skepsis gegenüber rassekundlichen Konzepten. ${ }^{36}$ So findet das bekannte Lagarde-Zitat: „Das Deutschtum liegt nicht im Geblüte, sondern im Gemüte.“ eine gewisse Entsprechung in einer Formulierung Renans: „La religion de la humanité, établie non sur le sang, mais sur le cœur“. ${ }^{37}$

Auch in Bezug auf die Person Jesu teilte Lagarde ${ }^{38}$ die Ansichten Renans: „[Das innerliche Wesen Jesu] bildete sich gerade im Gegensatze zu dem Judenthume seiner Zeit aus.“ Und weiter:

34 Renan. Correspondence Générale IV, 1856-1862. Textes réunis, classés et annotés par Maurice Gasnier sous la direction de Jean Balcou. Paris 2014. S. 29 - 32; 203-206; Niedersächsische Staatsund Universitätsbibliothek Göttingen: Nachlass Paul de Lagarde, Signatur: Cod. Ms. Lagarde $150: 967$.

35 Ich verweise hier lediglich auf die Überblicksdarstellung von Lattke, Michael: Paul Anton de Lagarde und das Judentum. Brisbane 2014 und auf die Beiträge von Armin Lange (in diesem Band S. 147-166) und Ina Ulrike Paul (in diesem Band S. 9-29).

36 Wie bei Renan finden sich in den Schriften Lagardes gleichwohl biologistische Metaphern. 37 Renan, Vie de Jésus (wie Anm. 29), S. 223.

38 Vgl. dazu: Schütte, Hans W.: Lagarde und Fichte. Die verborgenen spekulativen Voraussetzungen des Christentumsverständnisses Paul de Lagardes. Gütersloh 1965. S. 34-43; bes. 39-40; vgl. a. die einleitende Feststellung, S. 34: „Die Äußerungen Lagardes über den historischen Jesus sind von der theologischen Literatur weithin unbeachtet geblieben.“ 
Wenn Jesus als Prophet eine Form israelitischen Geisteslebens erneuerte, so war er Stifter des Evangeliums, [...] als Empfinder der ewigen Wahrheit, [...] daß der gerade Gegensatz des von Israel der Art nach verschiedenen, wenn auch aus Israel entstandenen Judenthums das sei, worauf es in Zeit und Ewigkeit ankomme.

Israel war also vom Judentum zu trennen und letzterem galt Lagardes Ablehnung. Auch Jesus hätte „nicht Jude, [...], nicht Mitglied irgend einer Nationalität sein“ wollen. ${ }^{39}$ Mochte Jesus also ethnisch ein Israelit oder Hebräer sein, ${ }^{40}$ kulturell hätte er mit den seinerzeitigen Vertretern jüdischer Religion nichts mehr gemein gehabt.

Lagarde und Renan wollten Jesus nicht „rassisch“ „entjudaisieren“, ${ }^{41}$ das Christentum aber als eine radikale Abkehr vom Judentum verstanden wissen und dabei insbesondere auch die Religion von dem jüdischen „nationalen“ Bezugsrahmen ablösen. Während aber Renan ein Verschwinden der verschiedenen Rassen erwartete und an einen aufgeklärt-rationalen Fortschritt glaubte, wünschte Lagarde der Religion einen neuen nationalen Bezugsrahmen zu geben: „Die germanischen Völker hingegen haben die Religion mit ihrer Nationalität in Beziehung zu setzen.“42

Demnach hätten die Juden, oder besser die Hebräer zwar dem Christentum die Grundlage (Monotheismus) bereitet. ${ }^{43}$ Dieses habe sich aber gegen das jüdische Konzept der Auserwähltheit und die damit verbundene Abgrenzung als universelle Religion durchsetzen müssen:

[S]eit das Alte Testament dem Neuen Testamente Platz gemacht hat, und die christliche Kirche entstanden ist, sind die Juden trotz des Papiermaché-Monotheismus, den sie zur Schau tragen, Heiden. ${ }^{44}$

Inzwischen aber, so Lagarde, müsse die Religion re-nationalisiert werden: „Weltreligion im Singulare und nationale Religionen im Plurale, das sind die

39 Lagarde, Paul de: Die Religion der Zukunft. In: Deutsche Schriften 1. Göttingen 1878. S. 246; vgl. Fenske, Wie Jesus zum Arier wurde (wie Anm. 26), S. 81-83.

40 Vgl. Lagarde, Die Religion der Zukunft (wie Anm. 38), S. 246: „Jedes Volk vermag Nachblüthen seines eigensten Wesens zu treiben: Jesus war eine solche von Israel.“

41 Allerdings habe das jüdische „Volk“ Jesus ans Kreuz geschlagen; vgl. dazu Lattke, Paul Anton de Lagarde (wie Anm. 34), S. 48, Anm. 12 und weiter auf S. 49 eindeutig: „Gegen diejenigen, die Lagardes Antisemitismus als nicht rassisch begründet verteidigt oder als nicht rassisch genug kritisiert haben, muss festgestellt werden, dass er die Juden durchaus als ,Rasse bezeichnet hat.“ 42 Lagarde, Die Religion der Zukunft (wie Anm. 38), S. 254.

43 Hierzu Lattke, Paul Anton de Lagarde (wie Anm. 34). S. 50, Anm. 18.

44 Lagarde, Paul de: Juden und Indogermanen. In: Ausgewählte Schriften. Hrsg. v. Paul Fischer. München 1924. S. 209. 
Programmworte der beiden Gegner.“45 Renan, wiewohl ein „abtrünniger“ Katholik konnte dem nicht zustimmen, auch weil seine Auffassung von Nationen sich von der Lagardes unterschied. Im Nachgang des deutsch-französischen Krieges schrieb er an den Theologen David Friedrich Strauss (1808-1874):

Notre politique c'est la politique de droit des nations, la vôtre c'est la politique des races [...]. La division trop accusée de l'humanité en races, outre qu'elle repose sur une erreur scientifique. [...] Vous avez levé dans le monde le drapeau de la politique ethnographique et archéologique en place de la politique libérale, cette politique vous sera fatale. ${ }^{46}$

Die Mahnungen Renans verhallten bekanntermaßen ungehört. Bei Lagarde findet sich allerdings bereits angelegt, was die nachfolgende Diskussion um das Verhältnis von Judentum, Christentum und Deutschtum im deutschen akademischen Betrieb bestimmen sollte: Von den Juden wollte man allenfalls die (monotheistischen) Grundlagen der christlichen Religion akzeptieren, sich dabei aber gegen das Judentum als eine „Nationalreligion“ positionieren und gleichzeitig das Christentum national, oder besser völkisch umdeuten und dadurch vereinnahmen.

\section{Vollendetes Judentum - Eduard Meyer (1855-1930)}

Der Althistoriker Eduard Meyer darf als einer der letzten altertumswissenschaftlichen Universalgelehrten angesehen werden. ${ }^{47}$ Sein noch $\mathrm{zu}$ Schulzeiten gefasster Plan, neben der fundierten Ausbildung in den klassischen, auch semitische Sprachen zu studieren, konnte erst nach einem Studienortwechsel von Bonn nach Leipzig im Wintersemester 1872 richtig umgesetzt werden. Hier befand er sich allerdings im Zentrum der damaligen deutschen Orientalistik. ${ }^{48}$ In Leipzig widmete er sich auch schon dem Studium der antiken Religionsgeschichte und wurde 1875 bei dem Ägyptologen Georg Ebers (1837-1898) mit einer Arbeit über den ägyptischen Gott „Seth-Typhon“ promoviert. 1879 habilitierte er sich dann

45 Lagarde, Die Religion der Zukunft (wie Anm. 38), S. 254. Er bezog sich dabei natürlich auf die römisch-katholische Kirche und den Protestantismus, der nur „durch die germanische Naturanlage“ (ebd.) erfolgreich gewesen sei.

46 Renan, La réforme intellectuelle et morale (wie Anm. 15), S. 109.

47 Vgl. Marohl, Heinrich: Eduard Meyer Bibliographie. Mit einer autobiographischen Skizze Eduard Meyers und der Gedächtnisrede von Ulrich Wilcken. Stuttgart 1941.

48 Mangold, Eine „weltbürgerliche Wissenschaft“ (wie Anm. 7), S. 91-96; 151-155. 


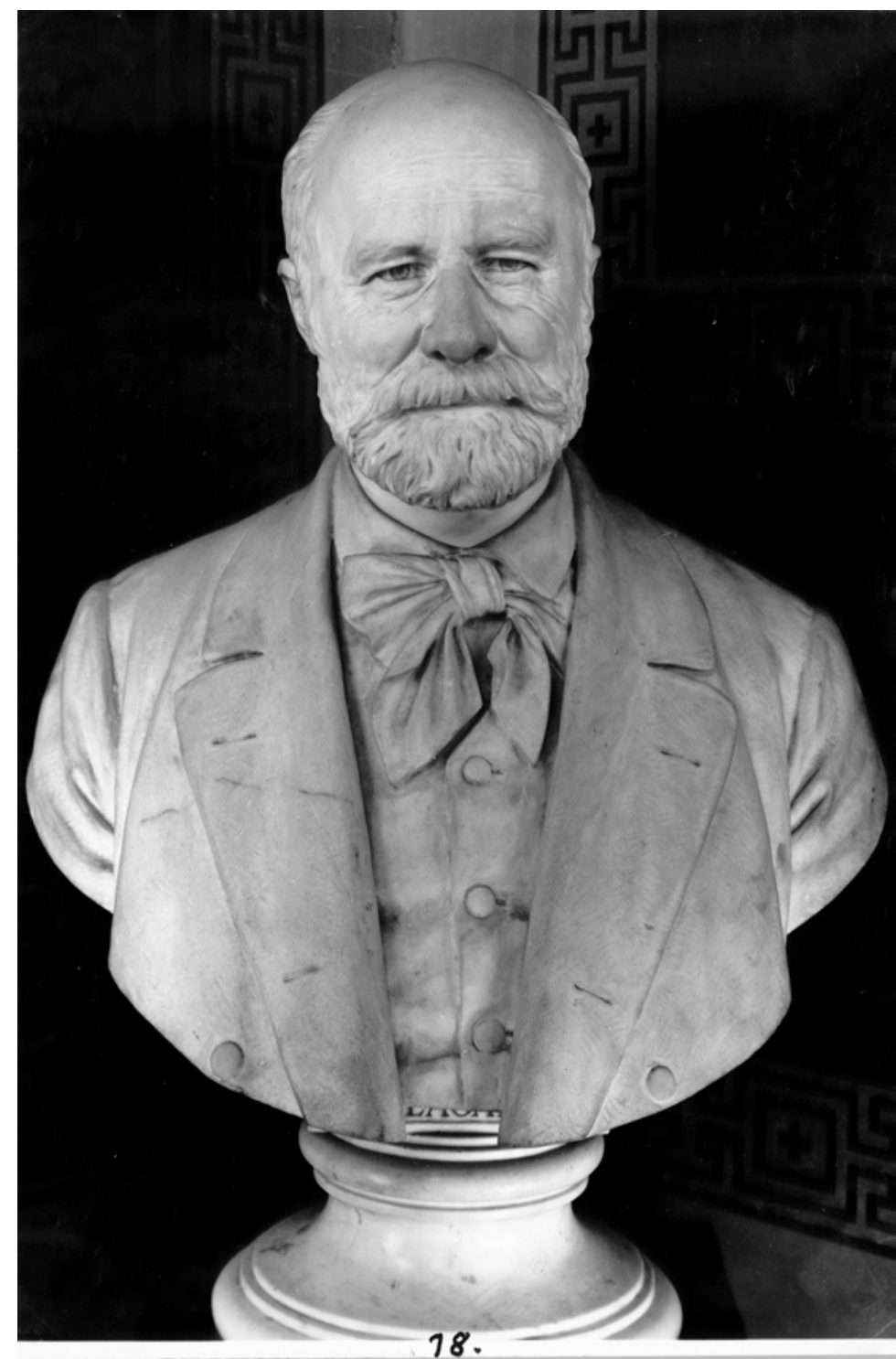

Abb. 6: Büste Paul de Lagardes von Carl-Ferdinand Hartzer (C) Niedersächsische Staats- und Universitätsbibliothek Göttingen

allerdings für das Fach Alte Geschichte. 1885 wurde er zum Ordinarius in Breslau berufen, 1889 auf den Lehrstuhl in Halle, bis er schließlich 1902 den Ruf an die Universität Berlin annahm. Während des Ersten Weltkrieges profilierte Meyer sich 
in zahlreichen Publikationen als Deutschnationaler und trat auch für weitreichende Annexionen von Gebieten in Osteuropa ein. ${ }^{49}$ Nach Kriegsende wurde er folgerichtig Mitglied der Deutschnationalen Volkspartei (DNVP). ${ }^{50}$

Die religionsgeschichtliche Auseinandersetzung Meyers mit Juden und Judentum $^{51}$ steht in engem Verhältnis mit seiner Darstellung der Entstehung des Christentums. ${ }^{52}$ Meyers grundsätzliche Ablehnung isolierter nationaler Geschichtsschreibung korrespondiert dabei inhaltlich durchaus auch mit einer kritischen Haltung gegenüber jedwedem Sonderstatus des israelischen Volkes. ${ }^{53}$ Gleichwohl bringt er dem israelischen Nordreich gegenüber dem südlichen Nachbarn Juda mehr Sympathien entgegen. Unter dem Eindruck der quellenkritischen Erkenntnisse zum Alten Testament (re-)konstruiert Meyer ein vor-exilisches, nationalstaatliches Israel, ${ }^{54}$ welches weder mit der späteren, nach-exilischen Geschichtsschreibung noch mit der in Vorschriften erstarrten Gesetzesreligion des Judentums viel zu tun gehabt habe. ${ }^{55}$ Wie Renan gibt Meyer den Juden eine Mitschuld an den erlittenen Anfeindungen und Verfolgungen, die sich eben aus der nach-exilischen Abgrenzung gegen die Nicht-Juden ergeben habe:

Man fand zahlreiche absonderliche Anschauungen und abergläubische Riten und Bräuche, [...] und dazu eine hochmütige Überhebung und eine gehässige Absperrung, gegen alle Andersgläubigen. ${ }^{56}$

Einen positiven Einfluss auf das Judentum erkennt Meyer allerdings in der vermeintlichen Beeinflussung durch den „arischen“ Zoroastrismus: „Die neue Reli-

49 Ungern-Sternberg, Jürgen von: Politik und Geschichte. Der Althistoriker Eduard Meyer im Ersten Weltkrieg. In: Eduard Meyer. Leben und Leistung eines Universalhistorikers. Hrsg. v. William Calder III und Alexander Demandt. Leiden 1990 (Supplements to Mnemosyne). S. 484-504. 50 Grüttner, Michael et al. (Hrsg.): Die Berliner Universität zwischen den Weltkriegen 1918 - 1945. Berlin 2012 (Geschichte der Universität Unter den Linden 2). S. 22; 146.

51 Dazu: Hoffmann, Christhard: Juden und Judentum im Werk deutscher Althistoriker des 19. und 20. Jahrhunderts (Studies in Judaism in Modern Times 9). Leiden 1888. S. 133-189.

52 Vgl. Jantsch, Johanna: Die Entstehung des Christentums bei Adolf Harnack und Eduard Meyer. Bonn 1990. S. 161-174.

53 Meyer, Eduard: Kleine Schriften zur Geschichtstheorie. Zur Geschichtstheorie und zur wirtschaftlichen und politischen Geschichte des Altertums. Halle a.d.S. 1910. S. 41.

$54 \mathrm{Vgl}$. Hoffmann. Juden und Judentum (wie Anm. 50). S. 140.

55 Mit dieser Grundopposition: Israel-Judentum entsprach er allerdings auch ganz dem Zeitgeist; dazu: Liebeschütz, Hans: Das Judentum im deutschen Geschichtsbild von Hegel bis Max Weber. Tübingen 1967. S. 272-276.

56 Meyer, Eduard: Ursprünge und Anfänge des Christentums 2: Die Entwicklung des Judentums und Jesus von Nazaret. Berlin 1925. S. 31-32. 
gion [...] wurzelt in der altüberkommenen Vorstellungswelt der arischen Stämme“. ${ }^{57}$ Jesus wiederum hält er „für einen echten Juden, dessen ganze Denkweise und Anschauungen auf dem Boden des Phariseismus [sic] erwachsen sind."58 Darin erkennt Meyer aber eine eigene „pharisaeische Religion“59 in Opposition zum traditionellen Judentum. Bemerkenswerterweise hatte Mitte des 19. Jahrhunderts Abraham Geiger (1810 - 1874) ebenfalls Jesus als Pharisäer, durchaus in Opposition zum traditionellen Judentum, gesehen. Gerade deswegen jedoch hatte er ihn immer noch als Repräsentant des Judentums aufgefasst und damit Ernest Renan widersprochen, der eben diesen pharisäischen Hintergrund Jesu bestritt. ${ }^{60}$

Für Meyer jedoch erscheint Jesus als „Vollender des Judentums““. ${ }^{61}$ Seine entscheidende religionsgeschichtliche Leistung bestehe in der Aufhebung der Auserwähltheit des jüdischen Volkes, des Konzeptes einer Nationalreligion: „Bei Jesus dagegen und im Christentum ist diese nationale Auffassung völlig abgestreift.“62 Dennoch mag Meyer das Christentum nicht zu sehr mit dem „Juden“ Jesus in Beziehung setzen:

Jesus will das Gesetz nicht aufheben, sondern erfüllen, die neue Religion entsteht aus den Konsequenzen seiner Lehre ohne und gegen seinen Willen. ${ }^{63}$

Auch bei Meyer erkennt man das schon durch Renan und Lagarde gezeigte Bemühen, die geistigen Grundlagen des Christentums in seinen alttestamentlichen Ursprüngen zu erhalten, gleichzeitig aber jüdische Elemente darin möglichst auszuschließen. Bei Meyer treten hierzu einige Varianten bzw. Erweiterungen in Erscheinung: Das Judentum habe „arische“ Einflüsse durch den Kontakt mit den persischen Zoroastriern aufgenommen und an das Christentum weitergegeben. Jesus, obwohl selbst ein Jude, hat das Judentum „vollendet“ und damit den Weg frei gemacht für ein neues Kapitel der Religionsgeschichte. Wie Renan und La-

57 Meyer, Ursprünge und Anfänge 2 (wie Anm. 56), S. 59; vgl. Parente, Fausto: Die Entstehung des Judenthums: Persien, die Achämeniden und das Judentum in der Interpretation von Eduard Meyer. In: Eduard Meyer. Leben und Leistung eines Universalhistorikers. Hrsg. v. William M. Calder III und Alexander Demandt. Leiden 1990. S. 329-343.

58 So in einem Brief an Wilhelm II.; zitiert nach Jantsch, Die Entstehung des Christentums (wie Anm. 51), S. 168.

59 Vgl. Jantsch, Die Entstehung des Christentums (wie Anm. 51), S. 168-169, sowie Anm. 124, mit Verweis auf Hoffmann, Juden und Judentum (wie Anm. 50), S. 150, der sie bei Meyer als „theologische Schule“ auffasst.

60 Vgl. Heschel, Susannah: Der jüdische Jesus und das Christentum. Abraham Geigers Herausforderung an die christliche Theologie. Berlin 2001. S. 214; 221-224; 254-264.

61 Meyer, Ursprünge und Anfänge 2 (wie Anm. 56), S. 445.

62 Meyer, Ursprünge und Anfänge 2 (wie Anm. 56), S. 437.

63 Meyer, Ursprünge und Anfänge 2 (wie Anm. 56), S. 59. 
garde versuchte Meyer nicht, Jesus ethnisch zu „ent-judaisieren“, anders als die beiden, mochte er Jesus aber auch nicht als Religionsstifter des Christentums anerkennen. - Mit der Überwindung des Judentums erschöpft sich in Meyers Augen die religionsgeschichtliche Bedeutung Jesu.

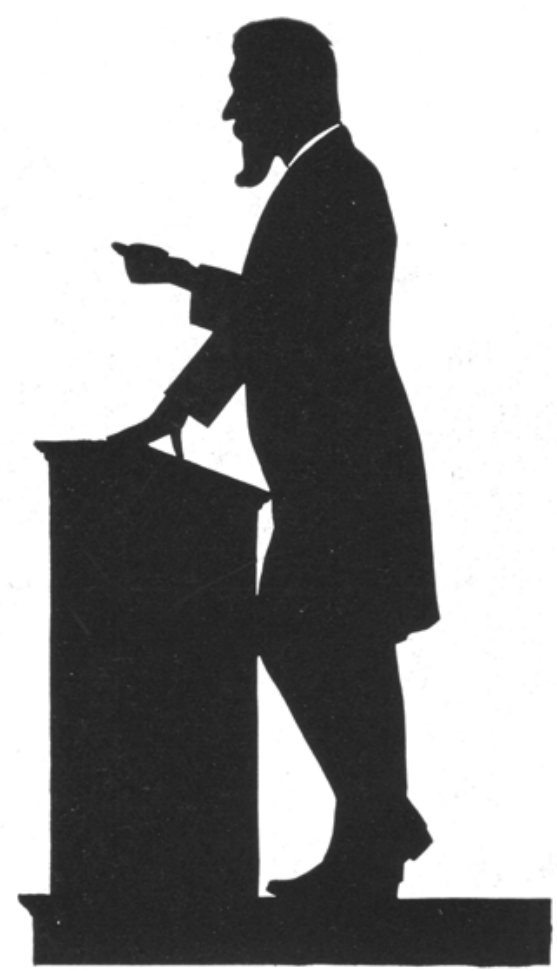

Prof. Dr. Eduard Meyer, Berlin

geschnitten von G. Lüling

Abb. 7: Scherenschnitt des Althistorikers Eduard Meyer auf einer alten Postkarte $\odot$ Privatbesitz des Verfassers 


\section{Babel und Bibel - Friedrich Delitzsch (1850-1922)}

Die Anführung Friedrich Delitzschs an letzter Stelle mag aufgrund seiner Lebensdaten - immerhin war er fünf Jahre älter als Eduard Meyer - verwundern, erklärt sich aber aus den Inhalten seiner Schriften zum Judentum, die mehr als die der zuvor behandelten Autoren anschlussfähig ${ }^{64}$ sind an nachfolgende Entwicklungen und in mancherlei Hinsicht einen Bruch mit dem „langen“ 19. Jahrhundert bedeuten.

Auch biografisch lässt sich dieser Bruch nachvollziehen: Delitzschs Vater, der lutherische Theologe Franz Delitzsch (1813-1890), ${ }^{65}$ betätigte sich u.a. auch als Aktivist der Judenmission. ${ }^{66}$ Reinhard Lehmann hat sich ausführlich mit der religiösen Prägung von Friedrich Delitzsch auseinandergesetzt. In diesem Zusammenhang stellt er fest: „Bei alledem kann ein unbewältigtes Verhältnis Friedrich Delitzschs zur neulutherischen Orthodoxie seines Vaters und der Theologie der Leipziger Fakultät nicht verwundern.“67 Die Emanzipationsbemühungen Delitzschs als Vertreter einer zunehmend selbstbewusster werdenden Altorientalistik sind durch die Aussagen von Suzanne Marchand bereits hervorgehoben worden. Man sollte sich allerdings davor hüten, Delitzsch als „ungläubigen Rationalisten“68 oder als direkten Vorläufer nationalsozialistischer Ideologie zu beschreiben. ${ }^{69}$

Friedrich Delitzsch ${ }^{70}$ begann sein Studium der indoeuropäischen und semitischen Sprachen 1868 in Leipzig und wechselte 1871 nach Berlin, wo er zusätzlich

64 Vgl. Vidal, Jordi: Adolf Hitler, Friedrich Delitzsch y el antisemitismo en los estudios bíblicos. In: Historiae 12 (2015). S. 65-80.

65 Smend, Rudolf: Franz Delitzsch - Aspekte von Leben und Werk. In: Die Erzväter in der biblischen Tradition. Festschrift für Matthias Köckert (Beihefte zur Zeitschrift für die alttestamentliche Wissenschaft. Hrsg. v. Anselm C. Hagedorn und Henrik Pfeiffer. Berlin 2009. S. 347366.

66 Küttler, Thomas: Umstrittene Judenmission. Der Leipziger Zentralverein für Mission unter Israel von Franz Delitzsch bis Otto von Harling. Leipzig 2009.

67 Vgl. Lehmann, Reinhard G.: Friedrich Delitzsch und der Babel-Bibel-Streit. Göttingen 1994 (Orbis Biblicus et Orientalis (OBO) 133). S. 64.

68 Vgl. ebenfalls ablehnend hierzu: Lehmann, Friedrich Delitzsch (wie Anm. 67), S. 77.

69 Vgl. die differenzierende Darstellung in: Ebach, Jürgen: Babel und Bibel oder: Das „Heidnische“ im Alten Testament. In: Die Restauration der Götter. Antike Religion und Neo-Paganismus. Hrsg. v. Richard Faber und Renate Schlesier. Würzburg 1986. S. 26-44.

$70 \mathrm{Zu}$ den biografischen Hintergründen: Delitzsch, Friedrich: Mein Lebenslauf. In: Reclams Universum 36 (1920). S. 241-246; Streck, Michael P.: Geschichte der Altorientalistik an der Uni- 
Äthiopisch erlernte. 1873 wurde er mit einer Arbeit über ,indogermanisch-semitische Wurzelverwandtschaft" promoviert. Sein ursprüngliches Vorhaben, sich in Jena für Sanskritistik zu habilitieren gab er auf und habilitierte sich stattdessen in Leipzig mit einer Arbeit zu „Assyrischen Studien“. 1877 wurde er außerordentlicher Professor für Assyriologie in Leipzig, 1885 ordentlicher Honorarprofessor. Ein Ordinariat wurde ihm jedoch verweigert und so folgte er 1893 einem Ruf nach Breslau, bevor er 1899 als Ordinarius für Orientalische Philologie und als Direktor des neugeschaffenen Vorderasiatischen Museums nach Berlin berufen wurde. Damit rückte Delitzsch ins Zentrum des damaligen (alt-)orientalistischen Wissenschaftsbetriebes und auch in die (nicht nur räumliche) Nähe der preußischdeutschen Kultur- und Wissenschaftspolitik. Die Nähe zwischen altorientalistischer Forschung und den deutschen politischen und wirtschaftlichen Eliten ${ }^{71}$ kam auch durch die 1898 erfolgte Gründung der Deutschen Orient-Gesellschaft (DOG) zum Ausdruck. ${ }^{72}$

Mit seinem 1902 in Anwesenheit des Kaisers ${ }^{73}$ gehaltenen populärwissenschaftlichen Vortrag zum Thema „Babel und Bibel“74 in der Singakademie in Berlin löste Friedrich Delitzsch eine heftige Grundsatzdebatte um das Primat altorientalischer Quellen gegenüber den Texten des Alten Testaments aus. ${ }^{75} \mathrm{An}$ dieser Stelle kann und soll keine erneute Behandlung dieser Auseinandersetzungen erfolgen. Deren Verlauf wird durch die anfängliche Unterstützung Wilhelms II. für Delitzsch und seine Thesen entscheidend mitbestimmt. Nachdem der

versität Leipzig. http://altorient.gko.uni-leipzig.de/Open\%20files/Altorientalistik.pdf (23.04. 2018). S. $1-4$.

71 Vgl. dazu: Hauser, Stefan R.: Deutsche Forschungen zum Alten Orient und ihre Beziehungen $\mathrm{zu}$ politischen und ökonomischen Interessen vom Kaiserreich bis zum Zweiten Weltkrieg. In: Comparativ 14 (2004), Heft 1. S. 46-65; Ders.: History, Races and Orientalism. Eduard Meyer, The Organization of Oriental Research, and Ernst Herzfeld's Intellectual Heritage. In: Ernst Herzfeld and the Development of Near Eastern Studies, 1900 -1950. Hrsg. v. Ann C. Gunter und Stefan R. Hauser. Leiden 2005. S. 505-513.

$72 \mathrm{Zu}$ den Hintergründen: Matthes, Olaf: Der Aufruf zur Gründung der Deutschen Orient-Gesellschaft vom November 1897. In: Mitteilungen der Deutschen Orient-Gesellschaft (MDOG) 130 (1998). S. 9-16; Matthes, Olaf und Althoff, Johannes: Die „Königliche Kommission zur Erforschung der Euphrat- und Tigrisländer“. Ebd. S. 241-254.

73 Zum archäologisch-kulturgeschichtlichen Interesse Wilhelms II. vgl. Franzen, Christoph J., Kohl, Karl-Heinz und Recker, Marie-Luise (Hrsg.): Der Kaiser und sein Forscher: Der Briefwechsel zwischen Wilhelm II. und Leo Frobenius (1924-1938). Stuttgart 2011; Beigel, Thorsten und Mangold-Will, Sabine (Hrsg.). Wilhelm II. Archäologie und Politik um 1900. Stuttgart 2017.

74 Delitzsch, Friedrich: Babel und Bibel. Ein Vortrag. 26. bis 30. Tausend, durch Anmerkungen erweitert. Leipzig 1903.

75 Die beiden wichtigsten Arbeiten dazu: Johanning, Klaus: Der Bibel-Babel-Streit. Eine forschungsgeschichtliche Studie. Frankfurt a.M. 1988, Lehmann, Friedrich Delitzsch (wie Anm. 67). 
Kaiser sein Wohlwollen zum Ausdruck gebracht und Delitzsch zur Wiederholung seines Vortrages ins Stadtschloss geladen hatte, hielt Delitzsch einen weiteren Vortrag zum Thema, ${ }^{76}$ in welchem er sich auch mit der wachsenden Zahl seiner Kritiker auseinandersetzte. Da er dabei aber den Charakter des Alten Testaments als göttliche Offenbarung in Zweifel stellte, entzog ihm Wilhelm, in seiner Eigenschaft als summus episcopus, öffentlich seine Unterstützung.

An dieser Stelle sollen einige Aussagen Delitzschs über Juden und Judentum und ihr Verhältnis zum Christentum vorgestellt werden. Die Reaktionen der Vertreter des deutschen Judentums können dabei nur kursorisch erwähnt werden. ${ }^{77}$ Kritik von dieser Seite hielt Delitzsch im Übrigen auch für nicht nachvollziehbar:

Dass Aufrollung dieser bedeutsamen theologischen, beziehungsweise religionsgeschichtlichen Fragen auch nur bei einiger Besonnenheit als eine Verletzung oder gar Beleidigung des Judentums, am allerwenigsten des modernen jüdischen Glaubens, nicht dauernd betrachtet werden wird, ist meine feste Ueberzeugung. ${ }^{78}$

Delitzsch lehnte sowohl den Offenbarungscharakter des Alten Testaments, wie auch die Auserwähltheit des Volkes Israel ab:

Diesen Monotheismus, welcher [...] alle übrigen Völker der Erde Jahrtausende hindurch ,ohne Hoffnung، sein liess und ,ohne Gott in der Welt‘, hält [sic] es schwer, für ,offenbart` zu halten von dem heiligen und gerechten Gott! ${ }^{79}$

Mit Jesus sieht Delitzsch „die Scheidewand“ zerrissen „zwischen orientalischisraelitischer“ und „christlich-philosophischer“ Weltanschauung. ${ }^{80}$ Die Schriften des Alten Testaments haben für ihn gleichwohl noch Bedeutung, wenn auch nur noch als „einzigartiges Denkmal eines grossen, bis in unsre [sic] Zeit hineinragenden religionsgeschichtlichen Prozesses. " ${ }^{81}$ Auf eine solche Kompromissformel wollten sich aber weder die Vertreter der christlichen Kirchen, der universitären Theologie, noch der Kaiser (zumindest offiziell) einlassen. An die Offenbartheit

76 Delitzsch, Friedrich: Zweiter Vortrag über Babel und Bibel. 1. bis 10. Tausend. Stuttgart 1903. 77 Vgl. dazu: Johanning, Der Babel-Bibel-Streit (wie Anm. 75), S. 219-247; Shavit, Yaacov und Eran, Mordechai: The Hebrew Bible reborn: From Holy Scripture to the Book of Books. Berlin 2007 (Studia Judaica 38). S. 195-352; Gertzen, Thomas L.: Die Vorträge des Assyriologen Friedrich Delitzsch über Babel und Bibel und die Reaktionen der deutschen Juden. Orientalismus und Antisemitismus in der Altorientalistik. In: Zeitschrift für Religion und Geistesgeschichte 71,3 (2019). S. 238-258.

78 Delitzsch, Zweiter Vortrag (wie Anm. 76), S. 41-42.

79 Delitzsch, Zweiter Vortrag (wie Anm. 76), S. 38.

80 Ebd.

81 Delitzsch, Zweiter Vortrag (wie Anm. 76), S. 39. 
der Heiligen Schrift durfte nicht gerührt werden. Für die Vertreter des deutschen Judentums ging es dabei natürlich um noch viel mehr: Delitzsch stellte die Grundlagen ihrer Religion in Frage, der er bestenfalls noch „Denkmalcharakter“ zubilligen wollte. Angesichts der heftigen Zurückweisung seiner Thesen und des gleichzeitig erlahmenden öffentlichen Interesses, hielt Delitzsch 1904 einen dritten Vortrag zum Thema. ${ }^{82}$ Anders als bislang ${ }^{83}$ jedoch, bemühte er nun stärker auch „rassische“ Argumentationsmuster. So sei das „Mischvolk der Galiläer und Samariter [...] durch Dorthinverpflanzung fremder Völkerschaften, obenan von Bewohnern babylonischer Städte“ durch die Assyrer in Israel heimisch geworden, was auch die angeblich zahlreichen Bezüge zu „Anschauungen, Aussprüchen und Taten, Jesu, des Galiläers“ nach Babylon erklären würde. ${ }^{84}$ Und: Die Babylonier seien nicht „reinsemitisch“. 85

Mit dem dritten und „Schlussvortrag“ kam die Babel-Bibel-Kontroverse zu einem vorläufigen Abschluss und sollte erst wieder durch „Die Grosse Täuschung“ (1921) aufgegriffen werden. Darin formulierte Delitzsch aber noch deutlicher und in unmittelbaren Anschluss an seine früheren Ausführungen die Konsequenzen, insbesondere aus seinen Erörterungen zu der ethnischen Zusammensetzung der Bevölkerung von Galiläa, wobei er Rassenzugehörigkeit wiederum mit Geisteshaltung in Verbindung bringt: ${ }^{86}$

Daß aber Jesu Vorfahren und Eltern, also auch Jesus selbst, nicht jüdischen Geblütes waren, [...] lehrt die ganze Geistesverfassung Jesu, die der jüdischen diametral entgegengesetzt war, [...]. Gegenüber dem israelitischen Nomadenvolk angeborenen exklusiv-partikularistischen Geistesart, die in der Abgesondertheit oder Heiligkeit des Volkes Israel dessen größten Vorzug erblickte und bis auf den heutigen Tag erblickt, sehen wir alles Reden und Tun Jesu

82 Delitzsch, Friedrich. Babel und Bibel. Dritter (Schluss-)Vortrag. 7. bis 10. Tausend. Stuttgart 1905.

83 Schon in Delitzsch, Babel und Bibel (wie Anm. 74). S. 19 hatte er eine Darstellung der Gemahlin des assyrischen Königs Assurbanipal als eine „Prinzessin arischen Geblüts“ identifiziert. 84 Delitzsch, Dritter (Schluss-)Vortrag (wie Anm. 82), S. 11; dazu: Arnold, Bill T. und Weisberg, David B.: A Centennial Review of Friedrich Delitzsch’s ,Babel und Bibel` Lectures. In: Journal of Biblical Literature (JBL) 121.3 (2002). S. 148.

85 Delitzsch, Dritter (Schluss-)Vortrag (wie Anm. 82), S. 11; 51, Anm. 8.

86 Es gilt dabei allerdings auch darauf hinzuweisen, dass das Thema mittlerweile weiter diskutiert worden war und sich der Ton entscheidend verschärft hatte. Ein Jahr vor der „Grossen Täuschung“ hatte z.B. der antisemitische Verschwörungstheoretiker Karl Weinländer (18701946) unter Pseudonym zum Verhältnis von Neuem Testament und germanischen Mythen publiziert: Döllinger, Friedrich: Baldur und Bibel. Weltbewegende neue Enthüllungen über die Bibel. Germanische Kultur im biblischen Kanaan und Germanisches Christentum vor Christus. Nürnberg 1920. Möglich ist also, dass Delitzsch den völkischen Autoren hinterhergerannt ist, um die Deutungshoheit behaupten zu können. 
beseelt, von erhabenster großzügigster Gesinnung, die in allen Völkern und Menschen der Erde gleichberechtigte Glieder der Menschheit erkannte. ${ }^{87}$

Ebenso wie durch die rassenkundlichen Spekulationen zur Person Jesu, war auch eine grundsätzlich ablehnende Haltung gegenüber dem Alten Testament bereits im letzten Babel-Bibel-Vortrag angelegt gewesen. Dieser begann mit der erklärten Zielsetzung eines „Urteil[s] über Wesen und Wert des althebräischen Schrifttums. “88 - Anfang der 20er Jahre lautete Delitzschs Urteil dann:

Die Erforschung des althebräischen Schrifttums, das uns Gottes Wesen und Walten so wenig offenbart als es vielmehr [...] Spiegelbild eines engherzigsten und zugleich unwürdigsten Gottesbegriffes ist, sollte deshalb auch nicht länger einen Zweig der christlichen Theologie bilden. ${ }^{89}$

Dabei zog Delitzsch vordergründig lediglich die Konsequenz aus einem fortschreitenden Prozess von Textkritik und Professionalisierung sowohl alttestamentlicher als auch altorientalistscher Forschung. Die „Zuständigkeit“ sollte von der Theologie auf die Altorientalistik oder die allgemeine Religionsgeschichte übergehen. Allerdings setzte er schließlich den „Wert“ des Alten Testaments ausdrücklich herab, bis hin zu der Feststellung:

Das sog. ,Alte Testament‘ ist für die christliche Kirche und damit auch für die christliche Familie vollkommen entbehrlich. Es wäre ungleich ratsamer, daß wir uns [...] in die tiefen Gedanken versenken würden, die unsere deutschen Geistesheroen über Gott und Jenseits und Unsterblichkeit gedacht haben und wie sie in Wilhelm Schwaners ,Germanen-Bibel ${ }^{190}$ so trefflich ausgewählt und geordnet zusammengestellt sind. ${ }^{91}$

Damit aber vollzog Delitzsch einen endgültigen Bruch: Das Alte Testament sollte nicht länger Gegenstand (christlich-)theologischer Forschung sein, weil es - in seinen Augen - vollkommen diskreditiert sei. Delitzsch versucht nicht länger Altes und Neues Testament, Judentum und Christentum miteinander zu versöhnen, sondern klar voneinander zu trennen. Damit ging er sehr viel weiter als Renan, Lagarde oder Meyer dies getan hatten, obwohl auch jene versuchten das

87 Delitzsch, Friedrich. Die Grosse Täuschung, Erster Teil: Kritische Betrachtungen zu den alttestamentlichen Berichten über Israels Eindringen in Kanaan, die Gottesoffenbarung vom Sinai und die Wirksamkeit der Propheten. Stuttgart 1921. S. 62.

88 Delitzsch, Dritter (Schluss-)Vortrag (wie Anm. 82), S. 3.

89 Delitzsch, Die Grosse Täuschung (wie Anm. 87), S. 97.

90 Schwaner, Wilhelm: Germanen-Bibel. Aus heiligen Schriften germanischer Völker. Schlachtensee 1920.

91 Delitzsch, Die Grosse Täuschung (wie Anm. 87), S. 97. 
Christentum von seinen jüdischen Ursprüngen zu entfernen. Allerdings weist Delitzschs Position Übereinstimmung mit der Forderung Lagardes auf, dem Christentum einen „germanischen“ Bezugsrahmen zu erschließen.

Delitzsch steht offensichtlich unter dem Einfluss der in Deutschland nach Ende des Ersten Weltkrieges erstarkenden völkischen Bewegung und versucht, wie viele Altorientalisten ${ }^{92}$ tendenziell weniger dem Credo „Ex oriente lux “93 als denn einem „Ex septentrione lux“ zu huldigen. ${ }^{94}$ Wichtig dabei aber ist, dass er zu dieser veränderten Anschauung durch die Auseinandersetzung mit den Kulturen des Alten Orients gelangte ${ }^{95}$ und zu diesem Zeitpunkt längst von sehr viel radikaleren Positionen überholt worden war. ${ }^{96}$

\section{Zusammenfassung und Ausblick}

Die Auswahl bzw. Begrenzung auf die hier vorgestellten Gelehrten und die Auseinandersetzung mit ihren Ansichten und Äußerungen über Juden und Judentum bringt notwendigerweise eine Verkürzung und Beschränkung mit sich. Mit vollem Recht könnte man den Wegfall einer der behandelten Personen oder die Berücksichtigung einer anderen fordern. In wie weit hier eine gewisse Repräsentativität erreicht werden konnte, ist v. a. deshalb in Frage zu stellen, da der Personalbestand orientalistischer Wissenschaft ohnehin recht klein ist, Einzelmeinungen dadurch zwar an (relativer) Bedeutung gewinnen, aber eben nicht mit dem Fach, bzw. den Fächern und ihren Forschungsergebnissen unmittelbar identifiziert werden sollten.

92 Hierzu: Voss, Susanne: Wissenshintergründe...- Die Ägyptologie als ,völkische‘ Wissenschaft entlang des Nachlasses Georg Steindorff von der Weimarer Republik über die NS- bis zur Nachkriegszeit. In: Georg Steindorff und die deutsche Ägyptologie im 20. Jahrhundert. Wissenshintergründe und Forschungstransfers, Berlin 2016. S. 106-112 und ebenso ihr Beitrag „Georg Steindorff und die völkische Ägyptologie“ (in diesem Band S. 93-107).

93 Ein Konzept, welches Delitzsch v. a. zu Werbezwecken für die Deutsche Orient-Gesellschaft bemüht hatte; vgl. Delitzsch, Friedrich: Ex Oriente Lux! Ein Wort zur Förderung der Deutschen Orient-Gesellschaft. Leipzig 1898.

94 Vgl. Wiwjorra, Ingo: „Ex oriente lux“ - „Ex septentrione lux“. Über den Widerstreit zweier Identitätsmythen. In: Prähistorie und Nationalsozialismus. Die mittel- und osteuropäische Urund Frühgeschichtsforschung in den Jahren 1933-1945 (Studien zur Wissenschafts- und Universitätsgeschichte 2). Hrsg. v. Achim Leube und Morton Hegewisch. Heidelberg 2002. S. 73-106. 95 Vgl. a. das Spiel mit dem „Licht“-Motiv in den Titel seiner Vorträge: Delitzsch, Friedrich: Mehr Licht. Die bedeutsamsten Ergebnisse der Babylonisch-Assyrischen Grabungen für Geschichte, Kultur und Religion. Leipzig 1907.

96 Vgl. etwa Döllinger, Baldur und Bibel (wie Anm. 86). 


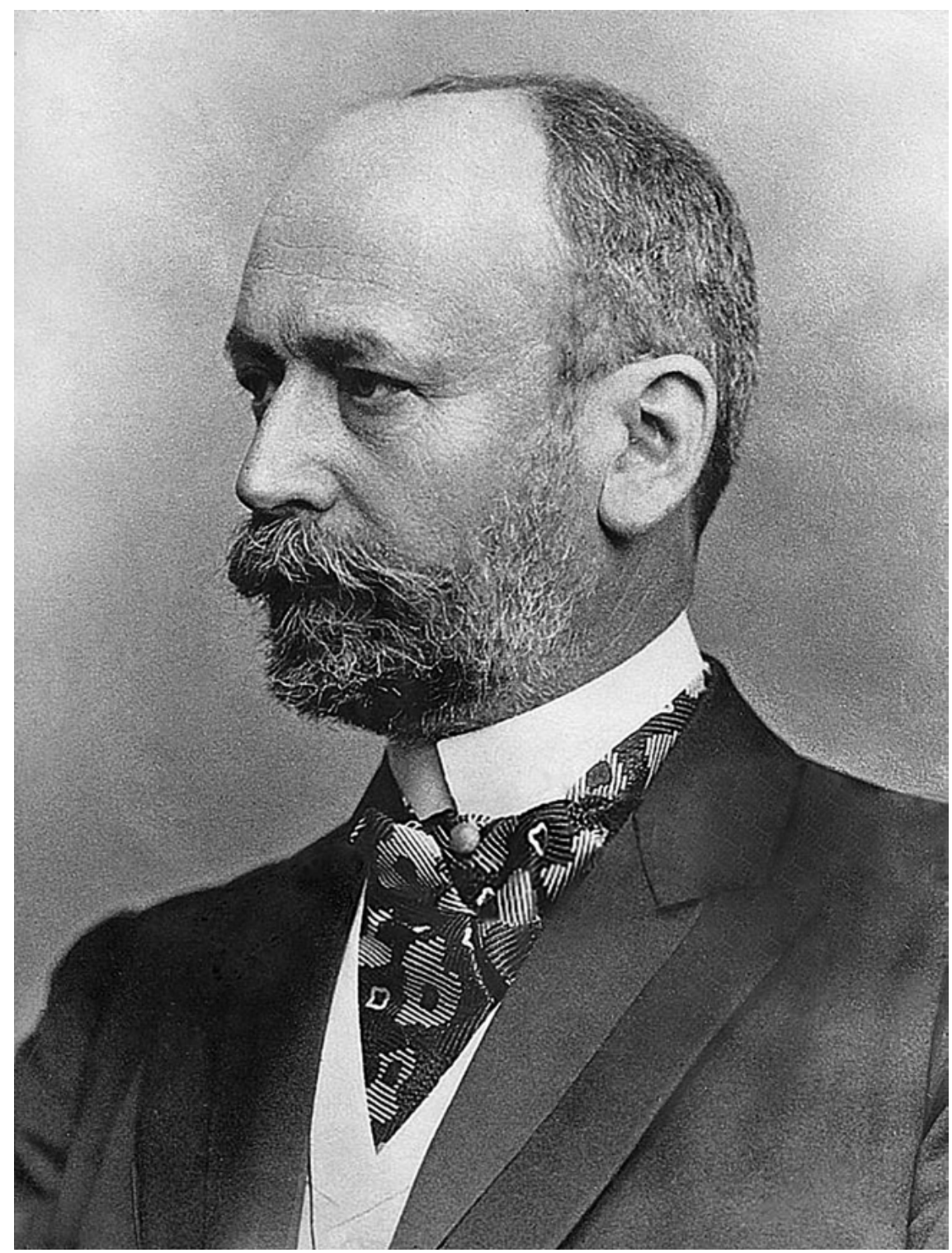

Abb. 8: Fotografie des Assyriologen Friedrich Delitzsch (C Gemeinfrei: https://commons.wikimedia.org/wiki/File:Friedrich_Delitzsch_2.jpg

Schon Zeitgenossen haben sich allerdings um Überblicksdarstellungen bemüht. So etwa der Rabbiner und Religionswissenschaftler Martin Mordekhai Schreiner (1863-1926), der in seiner 1902 veröffentlichten Streitschrift „Die 
jüngsten Urteile über das Judentum“, sowohl Paul de Lagarde als auch Eduard Meyer ausführlich behandelte. ${ }^{97}$ Auch der Delitzsch-Schüler und Assyriologe Paul Haupt (1858-1926) ${ }^{98}$ stützte sich bei seiner grundsätzlichen Kritik an dem nicht ausreichend differenzierenden Gebrauch der Begriffe „Semiten, Hebräer, Israeliten und Juden“ auf Ausführungen von Lagarde und Meyer, wobei er sich Lagardes Behauptung, diese Begriffsreihung stelle eine „absteigende Scala“99 dar, nicht anschließen wollte. ${ }^{100}$ Der unmittelbare persönliche Kontakt zwischen Renan und Lagarde ist ebenfalls angeführt worden.

Eine vergleichende Gegenüberstellung macht, wie eingangs ausgeführt, jedoch nur dann Sinn, wenn sich die Protagonisten in einen übergeordneten Untersuchungsrahmen einordnen lassen und sich aus Unterschieden und Übereinstimmungen, neben der Verortung des einzelnen Gelehrten, womöglich auch eine Entwicklungslinie ableiten lässt.

Im Kontext orientalistischer Forschung von zentraler Bedeutung ist das Begriffspaar von „Semiten und Ariern“. ${ }^{101}$ Alle der hier behandelten Gelehrten standen unter dem Eindruck dieses binären Konzepts. Das lag zunächst sicher an dem sprachlich-textlichen Zugang zu ihren jeweiligen Forschungsgegenständen, übertrug sich aber auf einen übergeordneten Gegensatz von „Orient“ und „Okzident".

Die Krux bestand für alle Gelehrten in der religionsgeschichtlichen Einordnung des Judentums. Einerseits bildete dieses die Grundlage des Christentums, andererseits war es nicht in einem evolutionären Prozess in diesem aufgegangen. Vor dem Hintergrund eines erwachenden Nationalismus, welcher zum Ende des 19. Jahrhunderts in Deutschland zunehmend in eine völkische Ideologie umschlug, stellten sich zusätzliche Herausforderungen ein: Die Grundlagen des (universellen) Christentums konnten nur schwer als ursprünglich exklusives Gottesverhältnis begriffen werden, doch der Fortbestand des Judentums schien genau dies weiter aufrechtzuerhalten. Der Glaube an die grundsätzliche Überlegenheit der „Arier“ über die „Semiten“, den bereits Renan so eindeutig formu-

97 Schreiner, Martin: Die jüngsten Urteile über das Judentum. Kritisch untersucht. Berlin 1902. Zu Lagarde: S. 65-87; zu Meyer: S. 99-116.

98 Welcher im Übrigen durch seine Habilitation zu einem angespannten Verhältnis zwischen seinem Lehrer und Lagarde beitrug; vgl. Sieg, Deutschlands Prophet (wie Anm. 31), S. 146-149; s.a. den Beitrag von Felix Wiedemann (in diesem Band S. 45-67).

99 Lagarde, Paul de: Mitteilungen 1. Göttingen 1884. S. 55.

100 Vgl. Haupt, Paul: Semites, Hebrews, Israelites, Jews. In: The Open Court 12 (1918). S. 753 - 760. 101 Dazu grundlegend: Olender, Maurice: Die Sprachen des Paradieses. Religion, Rassentheorie und Textkultur. Revidierte Neuausgabe. Berlin: 2013. S. 46 - 48; darin zu Renan: S. 87-102; weiterhin: Anidjar, Gil: Semites. Race, Religion, Literature. Stanford 2008 und Poliakov, Léon: Der arische Mythos. Zu den Quellen von Rassismus und Nationalismus. Hamburg 1993. 
lierte, machte es zudem schwierig, sich mit einem „jüdischen“, d.h. „semitischen“ Jesus abzufinden. ${ }^{102}$ Darauf reagierten die hier behandelten Gelehrten unterschiedlich: Renan mochte schon nicht mehr an die „Rassenreinheit“ der Galiläer glauben, anders als Delitzsch, kam es ihm auf diese aber auch grundsätzlich gar nicht an. Auch Lagarde maß der Rasse nur geringe Bedeutung zu, insofern, als dass nicht das Blut, sondern die Geisteshaltung Jesu entscheidend wäre und darin sei dieser ein Gegner des Judentums gewesen. Meyer bemühte sich ebenfalls, Jesus vom Judentum abzugrenzen, ihn als eine Art religiösen ,Konkursverwalter des Judentums darzustellen, der dann aber selbst nicht mehr das eigentliche Christentum begründet habe.

Allen Gelehrten gemeinsam ist die Ablehnung des Judentums. Mag es bei dem einen oder andern noch positive Aspekte aufweisen, so werden diese doch immer in eine weit zurückliegende und abgeschlossene Vergangenheit zurückverwiesen. Durch Jesus kommt diese zu einem endgültigen Abschluss - unabhängig davon, ob dieser selbst als Teil der überwundenen jüdischen Kultur begriffen wird oder nicht. Das rassische Argument spielt bei allen eine Rolle, aber sogar dann, wenn Jesus keine „rein-semitische“ Herkunft attestiert wird, sind es - auch bei Delitzsch - seine „Geistesverfassung“, seine „Reden und Taten“ die als ausschlaggebend dargestellt werden.

Die Argumentationsmuster und methodischen Zugänge der hier vorgestellten Gelehrten unterscheiden sich letztlich nur wenig voneinander, der diskursive Kontext verändert sich hingegen deutlich: Zum einen spiegelt sich in den Ausführungen die Schwerpunktverlagerung von einem vornehmlich religiös fundierten Antijudaismus hin zu einem rassenkundlich-biologistischen Antisemitismus wieder. ${ }^{103}$ Zum zweiten macht sich ein gewachsener akademischer Anspruch geltend. Orientalistische Forschung wird als ernstzunehmende Wissenschaft vertreten, religiöse Überzeugung tritt hinter vermeintlich objektiv ermittelte Fakten zurück.

Daraus ergeben sich zwei abschließende Fragestellungen: Erstens in wie weit können Ernest Renan, Paul de Lagarde, Eduard Meyer und Friedrich Delitzsch als Antisemiten gelten? Und zweitens: Sind ihre Einlassungen zu Juden und Judentum der Wissenschaftsgeschichte oder einer eher allgemeinen Kultur- und Geis-

102 Vgl. Arvidsson, Stefan: Aryan Mythology As Science and Ideology. In: Journal of the American Academy of Religion 67.2 (1999). Darin zu Renan: S. 336-338 und zu Lagarde: S. 338-339; Leutzsch, Martin: Der Mythos vom arischen Jesus. In: Vergangenheitsbewältigung im französischen Katholizismus und deutschen Protestantismus. Hrsg. v. Lucia Scherzberg. Paderborn 2008. S. $173-186$.

103 Zur Problematik des Konzepts einer linearen Entwicklung in diesem Bereich vgl. den Beitrag von Gideon Botsch und Werner Treß (in diesem Band S. 111-126). 
tesgeschichte zuzuordnen? Also anders gefragt: Spielt der mögliche Antisemitismus eine Rolle für die Fach- und Forschungsgeschichte, oder ist er letztlich doch Ausdruck einer subjektiven persönlichen Weltanschauung, die lediglich die wissenschaftlichen Publikationen der Gelehrten beeinträchtigt hat?

Die erste Frage ist von dem schon mehrfach erwähnten Problem einer allgemeingültigen Definition von Antisemitismus abhängig. Die Untersuchung der Argumentation und Thesen der hier vorgestellten Gelehrten sagt zunächst noch nichts über ihre Motivation aus. Fest steht, dass sie alle dem Judentum mit Ablehnung begegnet sind. Intensität und Argumentationsmuster mögen dabei variieren, an der grundsätzlichen Tendenz kann es keinen Zweifel geben. Der Referenzrahmen ist eindeutig ein akademischer. So ließe sich die erste Frage womöglich dahingehend eindeutig beantworten, dass alle vier durch ihre Schriften antisemitische Konzepte und Argumentationen bereitgestellt haben und, durch ihren Status als Wissenschaftler, diesen zusätzliches Gewicht verliehen.

Die zweite Frage ist (noch) schwieriger zu beantworten: Wo liegt die Grenze zwischen wissenschaftlicher Forschungsmeinung und persönlicher Haltung? Die Antwort darauf muss lauten, dass eine solche Grenze gar nicht gezogen werden kann. Insbesondere aber in der Orientalistik im Übergang vom 19. zum 20. Jahrhundert kommt dem einzelnen Wissenschaftler eine herausgehobene Bedeutung zu, so dass die Trennlinien noch weiter verschwimmen. Am Ende bleibt nur, die auffällige und weitreichende Übereinstimmung der Gelehrten festzustellen und ebenso die wechselseitige Beeinflussung von (orientalistischer) Wissenschaft und Zeitgeist.

Die mangelnde Eindeutigkeit und Klarheit dieser Einschätzungen mag frustrieren und sollte auf keinen Fall als Versuch einer Relativierung oder Verharmlosung missverstanden werden. Sie stellt aber das bei der gebotenen Notwendigkeit $\mathrm{zu}$ einer differenzierenden Betrachtung $\mathrm{zu}$ erreichende Optimum wissenschaftsgeschichtlicher Forschung dar. 